\title{
Dysphagia in the elderly in long-stay institutions - a systematic literature review
}

\author{
Miriam Allein Zago Marcolino ${ }^{1}$ \\ https://orcid.org/0000-0001-5333-3173 \\ Vanessa Souza Gigoski de Miranda ${ }^{1}$ \\ https://orcid.org/0000-0002-3332-9975 \\ Rafaela Soares Rech ${ }^{2}$ \\ https://orcid.org/0000-0002-3207-0180
}

Universidade Federal de Ciências da Saúde de Porto Alegre, Porto Alegre, Rio Grande do Sul, Brasil.

Universidade Federal do Rio Grande do Sul, Porto Alegre, Rio Grande do Sul, Brasil.

Conflict of interests: Nonexistent

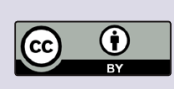

Received on: October 31, 2018 Accepted on: January 8, 2019

Corresponding address: Vanessa Souza Gigoski de Miranda Rua Sarmento Leite, 245. CEP: 90050-170 - Porto Alegre, Rio Grande do Sul, Brasil E- mail: vanessa_gigoski@hotmail.com
Commentary on the article "Dysphagia in the elderly in long-term institutions - systematic review of the literature" prepared by Santos BP, Andrade MJC, Silva RO, Menezes EC. Revista CEFAC. 2018; 20 (1): 123-30. https://dx.doi. org/10.1590/1982-021620182013817

The study by Santos et al. (2018) ${ }^{1}$ meets the growing need to synthesize evidence in health, specifically in the speech and language pathology area. However, after careful and careful reading, we verified some fragile aspects in the methodological scope, which affect the quality of this review. In general, we found a lack of general cohesion in the article, considering the described objective, the choice of the search terms, its eligibility criteria, the included studies and the conclusion of the authors.

According to the authors, "in order to revise aspects of dysphagia and indicators of risk in elderly swallowing, we sought to verify in the literature, through a systematic review, the dietary conditions of the elderly enrolled in long-stay institutions, seeking to observe the general care and agents that potentiate dysphagia in this population". For this, the authors stated that the search was performed through the Health Sciences Descriptors (DeCS) "Homes for the aged", "Aged" and "Deglutition Disorders" in the databases: PubMed, Latin American and Caribbean Literature in Health Sciences (Lilacs) and Scientific Electronic Library Online (SciELO).

The authors report that only literature reviews, controlled studies, and intervention studies addressing the topic of "swallowing and the elderly in long-term care facilities" would be selected, which, according to the researchers, follow the principles of systematic reviews that "only studies with levels of evidence one and two should be selected". However, this statement is not based on any reference for the development of systematic reviews, with Cochrane Collaboration being the main one among them.

The first point that we would like to analyze is the purpose of the study, which does not define a clear research question, and one of the main characteristics that differ a systematic review from of a narrative one is the definition of a research 
question, which bases the construction of the search strategy and the eligibility criteria of the studies ${ }^{2}$. With the objective of Santos et al. (2018), the population of interest is clear, but there is no definition between exposures and outcomes of interest.

In order to effectively evaluate what is published on the subject of interest, it is imperative that the databases relevant to the object of interest be properly chosen, as well as the keywords that make up the search strategy. An appropriate search strategy uses internationally recognized keywords ${ }^{1}$. Although DeCS are indexed terms, suitable for searches in LILACS and SCIELO databases, in PubMed, the terms Medical Subject Headings (MeSH), which are not equivalent to DeCS, are used as indexing descriptors. Thus, the search strategy used was not adequate for one of the main databases in the health area. The problem of not using indexed terms is that they serve to describe the subject of the indexed article in the database and make it easier for interesting studies to be found in searches ${ }^{3}$. In addition, the authors did not meet the eligibility criteria defined, since among the 11 studies included, only one is a systematic review ${ }^{4}$; all the others are observational, uncontrolled. Two studies do not include elders, but managers or staff of institutions ${ }^{5,6}$. Methodological rigor, with explicit and well-defined selection criteria in systematic reviews, minimizes research biases, providing more reliable results, with which conclusions can be made and decisions made ${ }^{2}$. When defined eligibility criteria are not followed, the review loses the systematic review feature and begins to present the same risks of biases as a narrative review.

Additionally, no instrument was used to assess the bias risk of the articles included in the research. Bias is a systematic error in conducting the study, with the risk of overestimating or underestimating the true effect of the intervention/exposure. The Cochrane Collaboration recommends the use of a specific tool to assess the risk of bias in each included study ${ }^{2}$, which would contribute to a quality analysis of the studies added in this review.

Finally, the conclusion of the study is not in line with the purpose of the article, stating that with this review, it was found that "long-term institutions do not provide adequate staffing for elderly care to reduce the risk of dysphagia," although the goal seems to be more related to identifying risk factors for the development of dysphagia in institutionalized older people than to investigating the composition of the teams at these institutions.
Through all the notes made, we consider that this review failed to obey the components of systematic reviews and should be interpreted as a narrative review. We also hope, with this letter, reinforce the importance of methodological rigor in conducting systematic reviews, which are one of the main sources of information for evidence-based practice.

\section{REFERENCES}

1. Santos BP, Andrade MJC, Silva RO, Menezes EdC. Dysphagia in the elderly in long-stay institutions-a systematic literature review. Rev. CEFAC. 2018;20(1):123-30.

2. Higgins J. Cochrane handbook for systematic reviews of interventions. Version 5.1. 0 [updated March 2011]. The Cochrane Collaboration. http:// www.cochrane-handbook.org. 2011.

3. Fatehi F, Gray LC, Wootton R. How to improve your PubMed/MEDLINE searches: 3. advanced searching, MeSH and My NCBI. Journal of telemedicine and telecare. 2014;20(2):102-12.

4. Pace CC, McCullough GH. The association between oral microorgansims and aspiration pneumonia in the institutionalized elderly: review and recommendations. Dysphagia. 2010;25(4):307-22.

5. Furkim AM, Duarte ST, Hildebrandt PT, Rodrigues $\mathrm{KA}$. The asylum as worsening factor for dysphagia. Rev. CEFAC. 2010;12(6):954-63.

6. de Oliveira JP, Marcolino JF, de Andrade MS. A formação do cuidador de idosos institucionalizados: Ênfase na rotina de alimentação. Estudos interdisciplinares sobre 0 envelhecimento. 2011;16(2):199-214. 